\title{
Determinants of self-rated private health insurance coverage in Jamaica
}

\author{
Paul A. Bourne ${ }^{1 *}$, Maureen D. Kerr-Campbell ${ }^{2}$ \\ ${ }^{1}$ Department of Community Health and Psychiatry, Faculty of Medical Sciences The University of the West Indies, Mona, Jamaica; \\ *Corresponding Author: paulbourne1@yahoo.com \\ ${ }^{2}$ Systems Development Unit, Main Library, The University of the West Indies, Mona, Jamaica
}

Received 18 November 2009; revised 5 January 2010; accepted 8 January 2010.

\section{ABSTRACT}

The purpose of the current study was to model the health insurance coverage of Jamaicans; and to identify the determinants, strength and predictive power of the model in order to aid clinicians and other health practitioners in understanding those who have health insurance coverage. This study utilized secondary data taken from the dataset of the Jamaica Survey of Living Conditions which was collected between July and October 2002. It was a nationally representative stratified random sample survey of 25,018 respondents, with $50.7 \%$ females and $49.3 \%$ males. The data was collected by way of a self-administered questionnaire. The non-response rate for the survey was $29.7 \%$ with $20.5 \%$ not responding to particular questions, $9.0 \%$ not participating in the survey and another $0.2 \%$ being rejected due to data cleaning. The current research extracted 16,118 people 15 years and older from the survey sample of 25,018 respondents in order to model the determinants of private health insurance coverage in Jamaica. Data were stored, retrieved and analyzed using SPSS for Windows 15.0. A p-value of less than 0.05 was used to establish statistical significance. Descriptive analysis was used to provide baseline information on the sample, and cross-tabulations were used to examine some non-metric variables. Logistic regression was used to identify, determine and establish those factors that influence private health insurance coverage in Jamaica. This study found that approximately $12 \%$ of Jamaicans had private health insurance coverage, of which the least health insurance was owned by rural residents $(7.5 \%)$. Using logistic regression, the findings revealed that twelve variables emerged as statistically significant determinants of health insurance coverage in this sample. These variables are social standing (two wealthiest quintile: $O R=1.68,95 \% \mathrm{Cl}=1.23-2.30$ ), income $(O R=1.00,95 \% \mathrm{Cl}=1.00-1.00)$, durable goods $(O R=1.16,95 \% \mathrm{Cl}=1.12-1.19)$, marital status (married: $O R=1.97,95 \% \mathrm{Cl}=1.61-2.42$ ), area of residence (Peri-urban: OR $=1.45,95 \% \mathrm{Cl}$ $=1.199-1.75$; urban: $O R=1.83,95 \% \mathrm{Cl}=1.40-$ 2.40 ), education (secondary: $\mathrm{OR}=1.57,95 \% \mathrm{Cl}=$ $1.20-2.06$; tertiary: $O R=9.03,95 \% \mathrm{Cl}=6.47-$ 12.59), social support $(\mathrm{OR}=0.64,95 \% \mathrm{Cl}=0.53$ -0.76 ), crowding (OR $=1.14,95 \% \mathrm{Cl}=1.02-$ 1.28), psychological conditions (negative affective: $\mathrm{OR}=0.97,95 \% \mathrm{Cl}=0.94-1.00$; positive affective: $O R=1.11,95 \% \mathrm{Cl}=1.06-1.16)$, number of males in household (OR $=0.85,95 \% \mathrm{Cl}=$ $0.77-0.93)$, living arrangements $(O R=0.62$, $95 \% \mathrm{Cl}=0.41-0.92)$ and retirement benefits $(O R=1.55,95 \% \mathrm{Cl}=1.03-2.35)$. This study highlighted the need to address preventative care for the wealthiest, rural residents and the fact that social support is crucial to health care, as well as the fact that medical care costs are borne by the extended family and other social groups in which the individual is (or was) a member, which explains the low demand for health insurance in Jamaica. Private health care in Jamaica is substantially determined by affordability and education rather than illness, and it is a poor measure of the health careseeking behaviour of Jamaicans.

Keywords: Health Insurance;

Private Health Coverage;

Social Determinants of Health Insurance Coverage; Jamaica 


\section{INTRODUCTION}

Literature on private health insurance or health insurance in the Caribbean, and in particular Jamaica, has been substantially on 1) population density-i.e. coverage, 2) coverage offerings, 3) cost of care-i.e. health economics, and 4) acceptance (or lack of) by health service providers of certain insurance coverage. Having extensively perused the literature review on private health insurance and health care reform in Jamaica, it is obvious that no study has been conducted identifying the different factors that explain health insurance coverage in this nation. The individual utilization pattern of health insurance coverage is highly associated over time with older adults $[1,2]$ as they prepare for the degeneration of the body; but, what else do we know about those who have private health insurance in Jamaica? Do insurers attract healthy patients, and are high risk individuals more likely to become insured as against their low risk (i.e. less health conditions) counterparts? Health insurance is a constituent of health seeking behaviour, suggesting that it is equally important in any study of health, quality of life, and wellbeing. In this study the researchers will critically examine factors that can be used to predict private health insurance coverage by using a logistic regression technique to explain the independent effect; and in the process the researchers will investigate the lives of respondents in order to understand those who reported having private health insurance coverage.

Instead of providing an elaborate and extensive description of 'health insurance', we will give a simplified meaning of this construct. Health insurance is protection against medical costs owing to the possibility of injuries, dysfunctions and other happenings that hinder the body from performing at some functional standard. In keeping with this definition, a health insurance policy is the contract that is signed by an insurer (i.e. insurance provider) and an individual or a group, in which the insurer agrees to pay a specific sum (i.e. a premium). Hence, the population's health service is partially dependent on health insurance coverage or the welfare system of the state. Jamaica does not have a public health insurance system, but one for the elderly and those who have particular chronic health conditions, such as diabetes mellitus, hypertension, cancer or a combination. In September 2001, the Cabinet of Jamaica accepted and approved a proposal for the establishment of a National Health Fund (NHF) that would assists patients as well as the elderly in Jamaicans. The individual benefits of the NHF (i.e. public health insurance options) for the elderly and for those with particular chronic health conditions was officially commenced in 2003 (i.e. August 1, 2003), and so there are only data on private health insurance coverage from 1988-2002. Despite the fact that Jamaica has instituted a free health-care service delivery programme for its child population (below 18 years in 2006), the quality of care which is relatively good is still surrounded by a certain socio-psychological milieu as well as inequality in health care offerings in the private versus the public sector. This explains the rationale why some people seek private health care and by extension private health insurance coverage [3] to meet the impending higher medical cost of care [1,4-7] and a particular quality of service-environment, customer service and length of service. The current study will be examined within the theoretical framework used by Franc, Perronnin, \& Pierre [8].

\subsection{Theoretical Framework}

A South African Health Inequalities Survey (SANHIS) carried out in 1994 of 3,489 women ages 16 to 64 years was used to model the determinants of health insurance coverage. Kirigia et al., [8] sought to model health insurance demand among South African women. They used binary logistic regression analyses to estimate health insurance coverage among the sample and various determinants of health insurance coverage. Health insurance coverage of the sample was determined by socio-demographic characteristics, health rating, environment rating, bad health choices (i.e. smoking and alcohol consumption), and contraceptives. These were embodied in the mathematical formula, Eq. 1:

$\mathrm{P}_{\mathrm{ij}}=\left(\alpha+\beta_{1}\right.$ Health rating $+\beta_{2}$ Environment rating $+\beta_{3}$ Residence $+\beta_{4}$ Income $+\beta_{5}$ Education $+\beta_{6}$ Age $+\beta_{7}$ Age squared $+\beta_{8}$ Race $+\beta_{9}$ Household size $+\beta_{10}$ Occupation $+\beta_{11}$ Employment $+\beta_{12}$ Smoking $+\beta_{13}$ Alcohol use $+\beta_{14}$ Contraceptive use $=\beta_{15}$ Marital status $+\varepsilon_{\mathrm{i}}$

where $P_{i j}=1$ if individual I owns insurance $(j=1)$ and equal otherwise $(j=0) ; \alpha$ is intercept terms; $(\beta$ 's $)$ are the estimated coefficients; and $\varepsilon_{\mathrm{i}}$ is the stochastic error term.

The conceptual framework of Kirigia et al.'s work [8] was on two risks of health care. They believed that these risks are (1) the risk of becoming ill, with the associated loss in quality of life, cost of medical care, loss of productive times, more serious cases, mortality, and (2) the risk of total or incomplete or delayed recovery [8]. This denotes that a person's decision to buy health insurance would be based on differentials between the level of expected utility of the insurance and the expected utility without insurance. It is this binary nature dependent variable and the desire to determine the effect of particular independent variables that justified the binary logistic regression technique.

Eq. 1 allows for the estimation of the individual probability of having or not having health insurance by some explanatory variables. Kirigia et al., [8] did not 
stipulate whether health insurance was public or private coverage, and this was addressed in another research paper. Using the same principle of econometric analysis as Kirigia et al., a group of researchers used a single multiple regression equation that identified explanatory variables and the powers of particular factors that can be used to determine determinants of those who have private health insurance [9]. This captures a standard utility theory model of a demand for private health insurance coverage, Eq. 2:

$$
\mathrm{Y}=\beta_{0}+\beta_{1} \mathrm{P}+\beta_{2} \mathrm{I}+\beta_{3} \mathrm{Z}
$$

where the standard utility theory is expressed in the quantity demanded of health insurance, $Y$, can be written as a function of the user price of health insurance, $P$, income, I, and a vector of other factors, $\mathrm{Z}$ or (with time subscripts suppressed); and $\beta_{1}$ and $\beta_{2}$ represent, respectively, the price and income elasticity of the demand for private health insurance.

Like Kirigia et al., [8] self-rated private health insurance coverage is a binary variable $(1=$ yes and $0=$ otherwise), which denotes that a logistic regression model will be used to estimate the determinants and determine their impact on the dependent variable, as was done by Ahking, Giaccotto, and Santerre [9]-Eq. 3. Instead of having a vector factor which envelopes individual characteristics, this research isolates those factors including income, unlike Eqs. 1 and 2, and added more variables such as psychological conditions, living arrangements and social support.

$\mathrm{HI}_{\mathrm{i}}=f\left(\mathrm{Y}_{\mathrm{i}}, \mathrm{HC}_{\mathrm{i}}, \mathrm{En}_{\mathrm{i}}, \mathrm{MS}_{\mathrm{i}}, \mathrm{AR}_{\mathrm{i}}, \mathrm{E}_{\mathrm{i}}, \mathrm{SS}_{\mathrm{i}}, \mathrm{O}_{\mathrm{i}}, \mathrm{P}_{\mathrm{i}}, \mathrm{G}_{\mathrm{i}}, \mathrm{NP}_{\mathrm{i}}, \mathrm{PP}_{\mathrm{i}}\right.$, $\mathrm{M}_{\mathrm{i}}, \mathrm{F}_{\mathrm{i}}, \mathrm{D}_{\mathrm{i}}, \mathrm{EW}_{\mathrm{i}}, \mathrm{A}_{\mathrm{i}}, \mathrm{R}_{\mathrm{i}}, \mathrm{YP}_{\mathrm{i}}, \mathrm{Pmc}_{\mathrm{i}}, \mathrm{LL}_{\mathrm{i}}, \mathrm{CR}_{\mathrm{i}}$ )

where Eq. 3 is Private Health Insurance coverage, $\mathrm{HI}_{\mathrm{i}}$, is a function of $\mathrm{Y}_{\mathrm{i}}$ is average current income per person in household $\mathrm{i} ; \mathrm{HC}_{\mathrm{i}}$ is health conditions of person $\mathrm{i} ; \mathrm{En}_{\mathrm{i}}$ is physical environment of person $\mathrm{i} ; \mathrm{MS}_{\mathrm{i}}$ is marital status of person $\mathrm{i} ; \mathrm{AR}_{\mathrm{i}}$ is area of residence of person $\mathrm{i} ; \mathrm{E}_{\mathrm{i}}$ is educational level of person $\mathrm{i} ; \mathrm{SS}_{\mathrm{i}}$ is social support of person $\mathrm{i}$; $\mathrm{O}_{\mathrm{i}}$ is average occupancy per person $\mathrm{i} ; \mathrm{P}_{\mathrm{i}}$ is property ownership of person $i$; $\mathrm{G}_{\mathrm{i}}$ is gender per person $\mathrm{i}$; $\mathrm{NP}_{\mathrm{i}}$ is negative affective psychological conditions per person $i$; $\mathrm{PP}_{\mathrm{i}}$ is positive affective psychological conditions per person $\mathrm{i} ; \mathrm{M}_{\mathrm{i}}$ is number of males per household per person $\mathrm{i}$; $\mathrm{F}_{\mathrm{i}}$ is number of females per household per person $\mathrm{i}$; $D_{i}$ is the number of children per household per person $i$; $E_{i}$ is durable goods; $A_{i}$ is age of person $i ; R_{i}$ is retirement benefits of person $i$; $Y_{\mathrm{i}}$ is social standing of person $i$; $P c_{i}$ is cost of medical care of person $i, L_{i}$ is living arrangements of person $\mathrm{i}$; and $\mathrm{CR}_{\mathrm{i}}$ is crowding.

The current study found the following determinants of private health insurance of Jamaica (Eq. 4):

$\mathrm{HI}_{\mathrm{i}}=f\left(\mathrm{Y}_{\mathrm{i}}, \mathrm{AR}_{\mathrm{i}}, \mathrm{MS}_{\mathrm{i}}, \mathrm{SS}_{\mathrm{i}}, \mathrm{E}_{\mathrm{i}}, \sum\left(\mathrm{NP}_{\mathrm{i}}, \mathrm{PP}_{\mathrm{i}}\right), \mathrm{M}_{\mathrm{i}}, \mathrm{EW}_{\mathrm{i}}, \mathrm{R}_{\mathrm{i}}\right.$, $\mathrm{YP}_{\mathrm{i}}, \mathrm{LL}_{\mathrm{i}}, \mathrm{CR}_{\mathrm{i}}$ ) where Eq. 4 is Private Health Insurance Coverage, $\mathrm{HI}_{\mathrm{i}}$, is a function of $\mathrm{Y}_{\mathrm{i}}$ is average current income per person in household $\mathrm{i} ; \mathrm{HC}_{\mathrm{i}}$ is health conditions of person $\mathrm{i} ; \mathrm{AR}_{\mathrm{i}}$ is area of residence of person $\mathrm{i} ; \mathrm{MS}_{\mathrm{i}}$ is marital status of person $\mathrm{i} ; \mathrm{SS}_{\mathrm{i}}$ is social support of person $\mathrm{i} ; \mathrm{G}_{\mathrm{i}}$ is gender per person $\mathrm{i}$; $\mathrm{E}_{\mathrm{i}}$ is educational level of person $\mathrm{i}$; $\mathrm{NP}_{\mathrm{i}}$ is negative affective psychological conditions per person $\mathrm{i}$; $\mathrm{PP}_{\mathrm{i}}$ is positive affective psychological conditions per person $\mathrm{i} ; \mathrm{EW}_{\mathrm{i}}$ is durable goods of person $\mathrm{i} ; \mathrm{D}_{\mathrm{i}}$ is the number of children per household per person $\mathrm{i}$; $\mathrm{Ri}$ is retirement benefits of person $\mathrm{i}, \mathrm{YPi}$ is social standing of person $\mathrm{i}, \mathrm{LL}_{\mathrm{i}}$ is living arrangements and $\mathrm{CR}_{\mathrm{i}}$ is crowding.

\section{MATERIALS AND METHODS}

\subsection{Method}

This study utilized secondary data taken from the dataset of the Jamaica Survey of Living Conditions which was collected between July and October 2002. It was a nationally representative stratified random sample survey of 25,018 respondents, with $50.7 \%$ females $(\mathrm{N}=12,675)$ and $49.3 \%$ males $(\mathrm{N}=12,332)$. The data was collected by way of an administered questionnaire. The non-response rate for the survey was $29.7 \%$ with $20.5 \%$ not responding to particular questions, $9.0 \%$ not participating in the survey and another $0.2 \%$ being rejected due to data cleaning. The current research extracted a subsample of 16,118 people 15 years and older from the survey sample of 25,018 respondents in order to model the determinants of private health insurance coverage in Jamaica.

The rationale for the use of the 2002 data set instead of the 2007 is primarily because of the sample population. In 2002, the institutions that were principally responsible for the data collection used $10 \%$ of the national population to gather pertinent data on the labour force, and this was for the Survey of Living Conditions. It represents the largest data collected on the Jamaican population, and data was also collected on crime and victimization and the environment, these being included for the first time, and omitted in subsequent surveys. Given the nature of crime, violence and victimization in the nation, we opted to use a survey that had crime and the environment as among data collected. Another condition for the selection of this dataset was the fact that it was a large population, as against other years when the population was less than 3,000. Within the context of a non-response rate that ranges from 10 to 30 per cent, a larger rather than a smaller sample size coupled with some pertinent variables was preferred to a smaller sample size without the two critical aforementioned variables. Data were stored, retrieved and analyzed using 
SPSS for Windows 15.0. A p-value of less than 0.05 was used to establish statistical significance. Descriptive analysis will be done on the sampled population in order to provide background information on the respondents; and the enter method of logistic regression will be used to establish the determinants of self-reported private health insurance in Jamaica. Using the principle of parsimony, the final model will consist of only those statistically significant variables. Where multicollinearity existed $(r>0.7)$, variables were independently entered into the model to aid in determining which one should be retained during the final model construction (i.e. the decision therefore was based on the variable's contribution to the predictive power of the model and the goodness of fit).

\subsection{Measure}

Health conditions: The summation of reported ailments, injuries or illnesses in the last four weeks, which was the survey period; where higher values denote greater health conditions; it ranges from 0 to 4 conditions. Health status is a dummy variable, where $1(\operatorname{good}$ health $)=$ not reporting an ailment or dysfunction or illness in the last four weeks, which was the survey period; 0 (poor health) if there were no self-reported ailments, injuries or illnesses. While self-reported ill-health is not an ideal indicator of actual health conditions as people may under-report their health condition, it is still an accurate proxy of ill-health and mortality. Household crowding: This is the average number of persons living in a room. Physical Environment: This is the number of responses from people who indicated suffering landsides; property damage due to rains, flooding or soil erosion. Psychological conditions are the psychological state of an individual, sub-divided into positive and negative affective psychological conditions. 18-19 Positive affective psychological condition signifies the number of responses with regard to being hopeful and optimistic about the future and life generally. Negative affective psychological condition means number of responses from a person on having lost a breadwinner and/or family member, loss of property, being made redundant, or failing to meet household and other obligations.

Income is proxied by total individual expenditure in USD. During the survey period, United States $\$ 1.00$ was equivalent to Jamaican $\$ 50.97$. Average income (i.e. per person per household) is total expenditure divided by the number of persons in the household. Age: The number of years lived, which is also referred to age at last birthday. This is a continuous variable, ranging from 15 to 99 years. Age group is classified into three categories. These are young adults (ages 15 to 30 years), middle aged adults (ages 31 to 59 years) and the elderly (ages
$60+$ years). Retirement benefits were measured by those who recei- ved retirement income. Private Health Insurance Coverage: This is a dummy variable, where $1 \mathrm{de}$ notes self- reported ownership of private health insurance coverage and 0 is otherwise.

Durable goods: This variable is the summation of the self-reported durable goods owned by an individual excluding houses, buildings and property. where $\mathrm{D}_{\mathrm{i}}$ $\mathrm{EW}=\sum_{i=1}^{28}\left(\mathrm{D}_{\mathrm{i}}\right)$ ranges from 1 to 28 , where higher values denote greater ownership of durable goods.

Living arrangements are a dummy variable where, $1=$ living alone, $0=$ living with family members or relative.

Social support (or network) denotes different social networks with which the individual has been or is involved ( $1=$ membership of and/or visits to civic organizations or having friends that visit one's home or with whom one is able to network, $0=$ otherwise).

Crime:

$$
\text { Crime Indexi }=\sum_{i=1}^{n}\left(K_{i} T_{j}\right)
$$

where $\mathrm{K}_{\mathrm{i}}$ represents the frequency with which an individual has witnessed or experienced a crime, where $i$ denotes 0,1 and 2, in which 0 indicates not witnessing or experiencing a crime, 1 means witnessing 1 to 2 , and 2 symbolizes seeing 3 or more crimes. $T_{j}$ denotes the degree of the different typologies of crime witnessed or experienced by an individual (where $\mathrm{j}=1 \ldots 4$, where $1=$ valuables stolen, 2 = attacked with or without a weapon, $3=$ threatened with a gun, and $4=$ sexually assaulted or raped. The summation of the frequency of crime by the degree of the incident ranges from 0 and a maximum of 51.

Social standing is proxied by per capita population quintile (from poorest-to-wealthiest)

\section{RESULTS}

\subsection{Demographic Characteristics of Sample}

The sample was 16,619 respondents (i.e. 48.6\% males and $51.4 \%$ females; with $39.2 \%$ young adults, $42.7 \%$ middle aged adults and $18.1 \%$ elderly). Some $25.8 \%$ of the sample resided in peri-urban areas; $60.2 \%$ in rural zones; $14.0 \%$ were from urban areas; $16.8 \%$ were below the poverty line (i.e. poorest 20\%); while $18.2 \%$ were just above the poverty line compared to $21.2 \%$ in the wealthy quintile and $24.1 \%$ in the wealthiest $20 \%$. Of the sample, $97.6 \%$ responded to the health status question. Of those who responded to the health status question, $80.6 \%$ indicated at least good health and 19.4\% poor health. Ninety-seven percentage points of the sam- 
ple $(n=16,118)$ responded to the health insurance coverage question, of that $11.9 \%$ revealed having health insurance coverage.

Based on Table 1, poverty is substantially a rural phenomenon. The findings revealed that $21.2 \%$ of rural residents were below the poverty line (i.e. poorest $20 \%$ ) compared to $10.7 \%$ of peri-urban dwellers and $9.5 \%$ of urban settlers. Health insurance was greatest among urban residents: Some $20.8 \%$ of urban dwellers had health insurance compared to $17.6 \%$ for peri-urban settlers and $7.5 \%$ of rural residents. A significant statistical difference was found between area of residence and crime, and income in this sample.

Peri-urban residents spent the most statistically on medical care (USD 39.16 \pm USD 85.77, 95\% CI: USD 31.39 - USD 46.94) compared to urban (USD $30.25 \pm$
USD 61.47, 95\% CI: USD 22.66 - USD 37.83) and rural residents (USD $29.33 \pm$ USD 54.15, 95\% CI: USD 26.58 - USD 32.06) (Table 1)

On examination of the cross tabulation between good health status and social standing, a statistical correlation was found ( $P=0.001)$ (Table 2). Table 2 showed that the worst health was reported by those in the wealthiest quintile $(21.8 \%)$, the poorest $(19.9 \%)$, the poor $(18.6 \%)$ and so on.

There is a positive statistical correlation between ageing and self-reported poor health (or health conditions) of Jamaicans ( $\mathrm{P}=0.001)$ (Table 3). Further examination of Table 3 revealed that $10.3 \%$ of young adults reported poor health compared to $17.4 \%$ of middle aged adults and $43.6 \%$ of the elderly

Table 1. Demographic characteristic of sample by area of residence.

\begin{tabular}{|c|c|c|c|c|}
\hline & Rural \% (n) & Peri-urban \% (n) & Urban \% (n) & $P$ \\
\hline Age group & & & & 0.001 \\
\hline Young adults & $38.3(3833)$ & $41.0(1760)$ & 39.7 (923) & \\
\hline Middle age adults & $41.6(4160)$ & $44.2(1895)$ & $44.6(1039)$ & \\
\hline Elderly & $20.1(2010)$ & $14.8(634)$ & $15.7(365)$ & \\
\hline Yes & $7.5(722)$ & $17.4(726)$ & $20.8(471)$ & \\
\hline No & $92.5(8969)$ & $82.6(3442)$ & $79.2(1788)$ & \\
\hline Gender & & & & 0.001 \\
\hline Male & $50.4(5041)$ & $46.8(2006)$ & $44.3(1031)$ & \\
\hline Female & $49.6(4962)$ & $53.2(2283)$ & $55.7(1296)$ & \\
\hline $1=$ Poorest $20 \%$ & $21.2(2118)$ & $10.7(458)$ & $9.5(222)$ & \\
\hline 2 & $22.0(2196)$ & $13.3(572)$ & $11.2(261)$ & \\
\hline 3 & $20.8(2085)$ & $18.7(800)$ & $16.7(388)$ & \\
\hline 4 & $19.8(1978)$ & $22.7(972)$ & $24.3(565)$ & \\
\hline $5=$ Wealthiest $20 \%$ & $16.2(1625)$ & $34.7(1487)$ & $38.3(891)$ & \\
\hline Marital status & & & & 0.001 \\
\hline Married & $25.5(2460)$ & $26.9(1115)$ & $21.0(475)$ & \\
\hline Never married & $66.6(6433)$ & $66.4(2755)$ & $71.6(1619)$ & \\
\hline Divorced & $0.6(56)$ & $1.0(41)$ & $1.2(26)$ & \\
\hline Separated & $1.1(104)$ & $1.2(49)$ & $1.4(32)$ & \\
\hline Crime index & $1.74 \pm 7.37$ & $2.34 \pm 8.08$ & $2.83 \pm 9.30$ & 0.001 \\
\hline Medical expenditure ${ }^{1}$ mean (SD) & $\$ 29.33 \pm \$ 54.15$ & $\$ 39.16 \pm \$ 85.77$ & $\$ 30.25 \pm \$ 61.47$ & 0.012 \\
\hline Income $^{2}$ mean $(\mathrm{SD})$ & $\$ 5496.12 \pm \$ 4860.97$ & $\$ 7534.74 \pm \$ 5544.26$ & $\$ 8779.26 \pm \$ 10568.69$ & 0.001 \\
\hline
\end{tabular}

${ }^{1}$ Medical Expenditure is expressed in USD: United States \$1.00 was equivalent to Jamaican $\$ 50.97$ (during surveyed period)

${ }^{2}$ Income is expressed in USD: United States $\$ 1.00$ was equivalent to Jamaican $\$ 50.97$ (during surveyed period) 
Table 2. Good health status by social standing (Per capita population quintile).

\begin{tabular}{ccccccc}
\hline \multirow{2}{*}{ Good health status } & \multicolumn{5}{c}{ Social standing (Per Capita Population Quintile) } \\
\cline { 2 - 6 } & 1=Poorest & 2 & 3 & 4 & $5=$ Wealthiest & Total \\
\hline Poor & 19.9 & 18.6 & 17.9 & 18.4 & 21.8 & 19.4 \\
Good & 80.1 & 81.4 & 82.1 & 81.6 & 78.2 & 80.6 \\
Total & 2738 & 2975 & 3208 & 3413 & 3883 & 16217 \\
\hline
\end{tabular}

$\chi^{2}(4)=23.273, P=0.001$, contingency coefficient $=0.038$

Table 3. Good health status by age group.

\begin{tabular}{ccccc}
\hline \multirow{2}{*}{ Good health status } & \multicolumn{3}{c}{ Age group } & Total \\
\cline { 2 - 5 } & Young age(15 to 30 years) & Middle age (31 to 59 years) & Elderly (60+ years) & \\
\hline Poor & 10.3 & 7.4 & 43.6 & 56.4 \\
Good & 89.7 & 82.6 & 2961 & 80.6 \\
Total & 6283 & 6973 & 16217 \\
\hline
\end{tabular}

$\chi^{2}(2)=1458.12, P=0.001$, contingency coefficient $=0.287$

\subsection{Multivariate Analysis}

Table 4 presents information on the variables which are correlated (or non-correlated) with private health insurance coverage in Jamaica of people 15 years and older. Using logistic regression, twelve variables emerged as statistically significant determinants of health insurance coverage in this sample (Table 4). These variables are social standing (two wealthiest quintiles: OR $=1.68$, $95 \% \mathrm{CI}=1.23-2.30)$, income $(\mathrm{OR}=1.00,95 \% \mathrm{CI}=$ $1.00-1.00)$, durable goods $(\mathrm{OR}=1.16,95 \% \mathrm{CI}=1.12-$ 1.19), marital status (married: $\mathrm{OR}=1.97,95 \% \mathrm{CI}=1.61-$ 2.42 ), area of residence (Peri-urban: OR $=1.45,95 \% \mathrm{CI}$ $=1.199-1.749$; urban: $\mathrm{OR}=1.831,95 \% \mathrm{CI}=1.395-$ 2.402), education (secondary: $\mathrm{OR}=1.57,95 \% \mathrm{CI}=1.20$ - 2.06; tertiary: $\mathrm{OR}=9.03,95 \% \mathrm{CI}=6.47-12.59)$, social support $(\mathrm{OR}=0.64,95 \% \mathrm{CI}=0.53-0.76)$, crowding $(\mathrm{OR}=1.14,95 \% \mathrm{CI}=1.02-1.28)$, psychological conditions (negative affective: $\mathrm{OR}=0.97,95 \% \mathrm{CI}=0.94$ -1.00 ; positive affective: $\mathrm{OR}=1.11,95 \% \mathrm{CI}=1.06-$ 1.16), number of males in household ( $\mathrm{OR}=0.85,95 \%$ $\mathrm{CI}=0.77-0.93)$, living arrangements $(\mathrm{OR}=0.62,95 \%$ $\mathrm{CI}=0.41-0.92)$ and retirement benefits $(\mathrm{OR}=1.55$, $95 \% \mathrm{CI}=1.03-2.35$ ).

The model [Eq. 4] had statistically significant predictive power (model $\chi^{2}=1604.389, P=0.001$; Hosmer and Lemeshow goodness of fit $\chi 2=5.280, P=0.727$ ), and correctly classified $91.3 \%$ of the sample (Correct classification of cases of reported health insurance coverage $=$ $32.0 \%$ and correct classification of cases with no insurance coverage $=98.3 \%$ ).

\section{DISCUSSION}

This study found that health insurance coverage is influenced by social standing, durable goods, income, marital status, area of residence, education, social support, crowding, psychological conditions, retirement benefits, living arrangements and the number of males in the household, and that those with good health are more likely to purchase health insurance than those with poor health. Continuing, rural residents, elderly and poorest, are the least likely to purchase health insurance coverage in Jamaica.

In the literature, it is well documented that the majority of uninsured workers in South Dakota were either employed or self-employed [6]. The poor, elderly and many rural residents are more likely to be employed on a seasonal basis in the informal sector, and these occupations and employment types do not have private health insurance, suggesting a further rationale for why unemployed people within a particular socio-economic status would be less likely to be holders of health insurance coverage. In this study, it was revealed that more uninsured Jamaicans were poor, elderly and from rural zones, and these were the ones most likely to be unemployed in Jamaica. The current study was not able to validate the direct claim of employability of the uninsured, but the elderly can indirectly validate the literature that more unemployed people do not have health insurance. In addition to the aforementioned fact, another finding was that poor health is associated with low income, owing to 
Table 4. Logistic regression: Private health insurance coverage by some variables.

\begin{tabular}{|c|c|c|c|c|}
\hline & \multirow{2}{*}{$P$} & \multirow{2}{*}{ Odds Ratio } & \multicolumn{2}{|c|}{ 95.0\% C.I. } \\
\hline & & & Lower & Upper \\
\hline Age & 0.443 & 1.00 & 0.99 & 1.00 \\
\hline Middle quintile & 0.174 & 1.24 & 0.91 & 1.71 \\
\hline Two wealthiest quintiles & 0.001 & 1.68 & 1.23 & 2.30 \\
\hline$\dagger$ Poorest 20\%-to-poor & & 1.00 & & \\
\hline Household Head & 0.213 & 1.80 & 0.71 & 4.55 \\
\hline Logged medical expenditure & 0.671 & 1.01 & 0.95 & 1.08 \\
\hline Average income & 0.009 & 1.00 & 1.00 & 1.00 \\
\hline Durable goods & 0.000 & 1.16 & 1.12 & 1.19 \\
\hline Separated or Divorced & 0.608 & 0.90 & 0.61 & 1.33 \\
\hline Married & 0.000 & 1.97 & 1.61 & 2.42 \\
\hline$\dagger$ Never married & & 1.00 & & \\
\hline Peri-urban & 0.000 & 1.45 & 1.10 & 1.75 \\
\hline Urban & 0.000 & 1.83 & 1.40 & 2.40 \\
\hline$\dagger$ Rural area & & 1.00 & & \\
\hline Environment & 0.116 & 0.85 & 0.70 & 1.04 \\
\hline House tenure - rented & 0.999 & 0.00 & 0.00 & \\
\hline House tenure - owned & 0.950 & 1.04 & 0.27 & 4.03 \\
\hline House tenure - squatted* & & 1.00 & & \\
\hline Secondary & 0.001 & 1.57 & 1.20 & 2.06 \\
\hline Tertiary & 0.000 & 9.03 & 6.47 & 12.59 \\
\hline$\uparrow$ Primary and below & & 1.00 & & \\
\hline Social support & 0.000 & 0.64 & 0.53 & 0.76 \\
\hline Sex & 0.722 & 1.03 & 0.86 & 1.24 \\
\hline Crowding & 0.018 & 1.14 & 1.02 & 1.28 \\
\hline Crime index & 0.652 & 1.00 & 0.99 & 1.01 \\
\hline Land ownership & 0.665 & 0.96 & 0.79 & 1.16 \\
\hline Negative affective & 0.034 & 0.97 & 0.94 & 1.00 \\
\hline Positive affective & 0.000 & 1.11 & 1.06 & 1.16 \\
\hline Number of males in house & 0.001 & 0.85 & 0.77 & 0.93 \\
\hline Number of females in house & 0.622 & 0.98 & 0.89 & 1.07 \\
\hline Number of children in house & 0.438 & 0.97 & 0.90 & 1.05 \\
\hline Living arrangement & 0.017 & 0.62 & 0.41 & 0.92 \\
\hline Retirement benefits $(1=$ yes $)$ & 0.038 & 1.55 & 1.03 & 2.35 \\
\hline Poor health status & 0.309 & 0.94 & 0.83 & 1.06 \\
\hline
\end{tabular}

-2Log Likelihood $=3982.175$

Nagelkerke R Square $=0.359$

Model $\chi^{2}(8)=1604.389$, P-value $=0.001$

Hosmer and Lemeshow $\chi^{2}=5.280, P=0.727$

Overall correct classification $=91.3 \%$ : Correct classification of cases of reported health insurance coverage $=32.0 \%$; Correct classification of cases with no health insurance coverage $=98.3 \%$

$\dagger$ Reference group 
the difficulties it creates with accessing crucial health care [6].

This research disagrees with the literature that the poor have lower health statuses, suggesting that they have more health-related conditions than the wealthy. The rich engage in highly involved particular lifestyle practices that expose them to health hazards, and this is not equally comparable to the poor environment of the poor, justifying why they reported the least health status. Pacione [10] has shown that the quality of the physical environment affects the quality of life (or health or wellbeing) of people, but that lifestyle behavioural practices play a significant role in determining one's health [11] like the physical milieu. [12,13] Moreover, the high cost of health care is a deterrent for the poor to have health insurance coverage; [6] and we concur with the literature as we found a positive statistical association between self-rated health insurance coverage and income. However, in this study we have refined the income variable, as there is a ceiling to income and its relation with the purchase of health coverage in Jamaica. The current work has revealed that those in the wealthy-to-wealthiest quintiles were twice as likely to purchase health insurance coverage as the poor-to-poorest people. Within the context that those in the wealthiest quintile purchased the most health insurance and indicated the lowest health status, it can be inferred that the purchase of health insurance is in keeping with their life style and the perceived role of income in buying good health, as against preventative behaviour.

Health insurance coverage is an elderly phenomenon, [6] and this work does not concur with the literature. The argument put forward is that younger people are healthier, and so do not see the need to invest in health coverage, as the risk of becoming ill is low, hence the willingness to engage in risky behaviour compared to their older counterparts, [6] suggesting that the futuristic end for health insurance coverage becomes even more critical after 30 years when more people will have families, as well as the fact that the purchase of health insurance may materialize owing to futuristic changes in the economic circumstances of the individual.

There is a statistical relationship between socioeconomic conditions and the health status of Barbadians, which is not the case in Jamaica. A study by Hambleton et al., [11] of elderly Barbadians revealed that $5.2 \%$ of the variation in reported health status was explained by the traditional determinants of health. Furthermore, when this was controlled for current experiences, the percentage fell to $3.2 \%$ (a drop of $2 \%$ ). When the current set of socioeconomic conditions was used, they accounted for some $4.1 \%$ of the variation in health status, while $7.1 \%$ were due to lifestyle practices compared to
$33.5 \%$ which were as a result of current diseases. [11] Despite this fact, it is obvious from the data that there are other indicators which explain health status; people do not necessarily pay attention to this fact although they may have more income or access to more economic resources. This explains the rationale for more health conditions being reported by the wealthiest as well as the group that purchased the most health insurance, where the thinking is that money can buy health.

A study published in the Caribbean Food and Nutrition Institute on the elderly in the Caribbean found that $70 \%$ of individuals who were patients within different typologies of health services were senior citizens. [14-16] Among the many issues that the research reported on are the five major causes of morbidity and mortality, taken from the Caribbean Epidemiology Centre, which are of paramount importance to this discussion, and their influence on the elderly - cerebrovascular, cardiovascular, neoplasm, diabetes, hypertension and acute respiratory infection-and these dysfunctions are highly costly to treat. It should be noted that many of these dysfunctions are owing to lifestyle behaviour. Hence, the purchase of private health insurance coverage by these people when they become old and approach retirement is in keeping with the cost of health care and the high likelihood of becoming ill.

Eldemire, [17] on the other hand, opined that the elderly are not as sick as some people are making them out to be-"The majority of Jamaican older persons are physically and mentally well and living in family units" [17]; but the fact is they are preparing for the eventuality of health conditions owing to the principle of the degeneration of the body with the onset of old age. Eldemire is somewhat right. The current study found that for every 1 young adult who reported poor health, there were approximately 2 middle aged adults and 4 elderly persons. Simply put, there were elderly people with poorer health than other age cohorts; but of the elderly, more of them indicated good health status $(56.4 \%)$. The mere fact of living longer (life expectancy post retirement is at least 15 years), suggests that the aged population will require more for medical care if they become ill. [18] With ageing the issue is not if they become ill but when. A group of scholars found that there is a direct association between ageing and health conditions, [19] a concept with which this study concurs. And this provides the explanation for the purchase of private health insurance more than other age cohorts, because they are at a different stage from other age cohorts in a population.

Health conditions are crucial to the purchase of primary health insurance coverage, and this is highlighted by ageing. Eldemire's works $[17,18]$ have shown that ageing in an individual does not translate to high physi- 
cal impairments, but that with ageing come particular changes in the profile of dysfunctions-Alzheimer's disease, dementia, cerebrovascular, cardiovascular, neoplasm, diabetes, hypertension and acute respiratory infection. [20] A study conducted by Costa [21], using secondary data drawn from the records of the Union Army (UA) pension programme that covered some $85 \%$ of all UA, shows that there is an association between chronic conditions and functional limitation-which includes difficulty walking and bending, blindness in at least one eye and deafness [21]. Among the significant findings is-(i) the predictability between congestive heart failure in men and functional limitation (i.e. walking and bending). Although Costa's study was on men, this applies equally to women, as biological ageing reduces physical functioning, and so any chronic ailment will only further add to the difficulties of movement of the aged, be it man or woman. One study has contradicted the works of Eldemire, and it showed that a large percentage of the elderly suffer from at least one health condition.

Women are more involved in health seeking behaviour, compared to their male counterparts, [22] irrespective of the age factor, and this is owing to the cultural background in which they live. Unlike women, across the world men have a reluctance to 'seek health-care' compared to their female counterparts. It follows in truth that women have bought themselves additional years in their younger years, and it is a practice that they continue throughout their lifetime which makes the gap in age differential what it is-approximately a 4-year differential in Jamaica. In keeping with the preventative care approach to health care, it would be expected that women would purchase more health insurance coverage than them, but this is not the case in Jamaica as gender was not a predictor of health status. However, the more men in a household, the less an individual will purchase health insurance coverage.

The Planning Institute of Jamaica in collaboration with the Statistical Institute of Jamaica has shown that while the general health status is commendable, chronic illnesses are undoubtedly eroding the quality of life enjoyed by people who are 65 years and older $[23,24]$. The JSLC report reveals that the prevalence of recurrent (chronic) diseases is highest among individuals 65 years and over. [23] The findings show that in 2000, the prevalence of self-reported illness/injury for people aged 65 years and over was $41.7 \%$, for those 60 to 64 years it was $27.6 \%$ compared to $19.8 \%$ for children less than five years old. However, the prevalence of self-reported illness/injury for those 50 to 59 years was $18.8 \%$. Some $36.6 \%$ of individuals 65 years and over reported injuries/illnesses in 2002 which is a $5.6 \%$ reduction in self-reported prevalence of illnesses/injuries over 2000, but the self-reported prevalence of illness/injuries rose by $25.8 \%$ to $62.4 \%$ in 2004 . [25,26] It should be noted here that this increase in self-reported cases of injuries/ailments does not represent an increase in the incidence of cases, as according to the JSLC for 2004, the proportion of recurring/chronic cases fell from $49.2 \%$ in 2002 to $38.2 \%$ in 2004 [26]. In addition, the PIOJ and STATIN [23] in (JSLC 2000) opined that individuals 60-64 years of age were 1.5 times more likely to report an injury than children less than five years of age, and the figure was even higher for those 64 years of age and older (2.5 times more). In this paper, the findings concurred with the literature that health conditions are significantly greater; but other issues account for them not demanding more health insurance coverage than middle age adults. This is reinforced in the findings that showed that people who received retirement benefits were approximately twice as likely to purchase health insurance coverage as those who did not receive any retirement benefits. Embedded in this finding is the fact that health insurance is a matter of affordability and education, and not illness, which justifies why rural residents had the lowest health insurance coverage, yet still the poorest $20 \%$ good health status was greater than that of those in the wealthiest $20 \%$. Statistics revealed that poverty in 2007 for the nation was $9.9 \%$, and rural poverty was $15.3 \%$ compared to $4 \%$ in peri-urban and $6.2 \%$ in urban areas [27], accounting for the lowest private health insurance coverage in that group.

\section{CONCLUSIONS}

In summary, married Jamaicans are more likely to purchase health insurance coverage compared to those who were never married, with urban residents being more likely to purchase health insurance than rural dwellers. An individual who has attained tertiary level education was more likely to purchase health insurance than one with at most primary level education, and those who lived alone were less likely to purchase health insurance coverage than those who dwelled with relatives or family members. Moreover the wealthiest were more likely to purchase health insurance, but were less healthy, and this indicates that income does not buy good health. Therefore, this study highlighted the need to address preventative care for the wealthiest, and the fact that social support is crucial to health care, along with the fact that medical care costs are borne by the extended family and other social groups in which the individual is (or was) a member, which explains the low demand for health insurance in Jamaica. 


\section{DISCLAIMER}

The researchers would like to note that while this study used secondary data from the Jamaica Survey of Living Conditions, none of the errors in this paper should be ascribed to the Planning Institute of Jamaica or the Statistical Institute of Jamaica, but to the researchers.

\section{ACKNOWLEDGEMENTS}

The author would like to take this opportunity to thank the Data Bank in Sir Arthur Lewis Institute of Social and Economic Studies, the University of the West Indies, Mona, Jamaica for making the dataset (i.e. Jamaica Survey of Living Conditions, 2002) available accommodated the current study.

\section{REFERENCES}

[1] Ettner, S.L. (1997) Adverse selection and the purchase of Medigap insurance by the elderly. Journal of Health Economics, 16(5), 543-562.

[2] Liu, T. and Chen, C. (2002) An analysis of private health insurance purchasing decisions with national health insurance in Taiwan. Social Science \& Medicine, 55(5), 755-774.

[3] Dong, H., Kouyate, B., Cairns, J., Mugisha, F. and Sauerborn, R. (2003) Willingness-to-pay for communitybased insurance in Burkina Faso. Health Economics, 12(10), 849-862.

[4] Carrin, G. (2003) Social health insurance in developing countries: A continuing challenge. International Social Security Review, 55(2), 57-69.

[5] Thomasson, M.A. (2006) Racial differences in health coverage and medical expenditure in the United States. Social Science History, 30(4), 529-550.

[6] The Lewin Group (2002) Health insurance coverage in South Dakota: Final report of the state planning grant program. South Dakota Department of Health.

[7] Varghese, R.K., Friedman, C., Ahmed, F., Franks, A.L., Manning, M. and Seeff, L.C. (2005) Does health insurance coverage of office visits influence colorectal cancer testing. Cancer Epidemiology Biomarkers \& Prevention, 14(3), 744-747.

[8] Kirigia, J.M., Sambo, L.G., Nganda, B., Mwabu, G.M., Chatora, R. and Mwase, T. (2005) Determinants of health insurance ownership among South African women. BMC Health Services Research, 5(1), 1-17.

[9] Ahking, F.W, Giaccotto, C. and Santerre R. (2009) The aggregate demand for private health insurance coverage in the US. Journal of Risk and Insurance, The American Risk and Insurance Association, 76(2), 133-157.

[10] Pacione, M. (2003) Urban environmental quality of human wellbeing - a social geographical perspective. Land- scape and Urban Planning, 65(1-2), 19-30.

[11] Hambleton, I.R., Clarke, K., Broome, H.L., Fraser, H.S., Brathwaite, F. and Hennis, A.J. (2005) Historical and current determinants of self-rated health status among elderly persons in Barbados. Rev Panam Salud Publica 2005, 17(5-6), 342-353.

[12] Bourne, P. (2007) Determinants of well-being of the Jamaican elderly. Master's Thesis, The University of the West Indies, Mona Campus.

[13] Bourne, P. (2007) Using the biopsychosocial model to evaluate the wellbeing of the Jamaican elderly. West Indian Medical Journal, 56(Suppl 3), 39-40.

[14] Caribbean Food and Nutrition Institute (1999) Health of the Elderly. Caribbean Food and Nutrition Institute Quarterly, 32, 217-240.

[15] Caribbean Food and Nutrition Institute (1999) Focus on the elderly. Caribbean Food and Nutrition Institute Quarterly, 32, 179-240.

[16] Anthony, B.J. (1999) Nutritional assessment of the elderly. Caribbean Food and Nutrition Institute Quarterly, 32, 201-216.

[17] Eldemire, D. (1995) A situational analysis of the Jamaican elderly 1992. The Planning Institute of Jamaica, Kingston.

[18] Eldemire, D. (1997) The Jamaican elderly: A socioeconomic perspective \& policy implications. Social and Economic Studies, 46(1), 75-93.

[19] Zimmer, Z., Martin, L.G. and Lin, H.-S. (2003) Determinants of old-age mortality in Taiwan. Policy Research Division Working Papers Series, 181, Population Council, New York. (http://www.popcouncil.org/pdfs/wp/181.pdf)

[20] Eldemire, D. (1996) Level of mental impairment in the Jamaican elderly and the issues of screening levels, caregiving, support systems, carepersons, and female burden. Molecular and Chemical Neuropathology, 28(1-3), 115 120.

[21] Costa, D.L. (2002) Chronic diseases rates and declines in functional limitation. Demography, 39(1), 119-138.

[22] Rice, P.L. (1998) Health psychology. Wadsworth Publishing, Belmont.

[23] Planning Institute of Jamaica and Statistical Institute of Jamaica (2001) Jamaica survey of living conditions 2000. Kingston.

[24] Planning Institute of Jamaica and Statistical Institute of Jamaica (1998) Jamaica survey of living conditions 1997. Kingston.

[25] Planning Institute of Jamaica and Statistical Institute of Jamaica (2003) Jamaica survey of living conditions 2002. Kingston.

[26] Planning Institute of Jamaica and Statistical Institute of Jamaica (2005) Jamaica survey of living conditions 2004. Kingston.

[27] Planning Institute of Jamaica and Statistical Institute of Jamaica (2008) Jamaica survey of living conditions 2007. Kingston. 